\title{
Effect of Carbon Coating on Scuffing Performance in Diesel Fuels*
}

\author{
O. O. Ajayi, M. F. Alzoubi, A. Erdemir, and G. R. Fenske,
}

\section{TECEIVED}

AUG 042000

\section{Q.STI}

Energy Technology Division

Argonne National Laboratory

Argonne, IL 60439

The submitted manuscript has been created by the University of Chicago as Operator of Argonne
National Laboratory under Contract No. W-31-109-ENG-38 with the U.S. Department of Energy.
The U.S. Government retains for itself, and others acting on its behalf, a paid-up, nonexclusive,
irrevocable worldwide ficense in said article to reproduce, prepare derivative works, distribute
copies to the pubbic, and perform publicly and display publicly, by or on behalf of the
Government.

February 2000

Paper to be presented at 2000 International Joint Tribology Conference, Oct. 1-4, 2000, Seattle

\footnotetext{
${ }^{*}$ Work supported by the U.S. Department of Energy, Office of Transportation Technologies, under Contract W-31-109-Eng-38.
} 


\section{DISCLAIMER}

This report was prepared as an account of work sponsored by an agency of the United States Government. Neither the United States Government nor any agency thereof, nor any of their employees, make any warranty, express or implied, or assumes any legal liability or responsibility for the accuracy, completeness, or usefulness of any information, apparatus, product, or process disclosed, or represents that its use would not infringe privately owned rights. Reference herein to any specific commercial product, process, or service by trade name, trademark, manufacturer, or otherwise does not necessarily constitute or imply its endorsement, recommendation, or favoring by the United States Government or any agency thereof. The views and opinions of authors expressed herein do not necessarily state or reflect those of the United States Government or any agency thereof. 


\section{DISCLAIMER}

Portions of this document may be illegible in electronic image products. Images are produced from the best available original document. 


\title{
Effect of Carbon Coating on Scuffing Performance in Diesel Fuels
}

\author{
O. O. Ajayi, M. F. Alzoubi, A. Erdemir, and G. R. Fenske,
}

Energy Technology Division

Argonne National Laboratory

Argonne, IL 60439

\begin{abstract}
Low-sulfur and low-aromatic diesel fuels are being introduced in order to reduce various types of emissions in diesel engines to levels in compliance with current and impending U.S. federal regulations. The low lubricity of these fuels, however, poses major reliability and durability problems for fuel injection components that depend on diesel fuel for their lubrication. In the present study, we evaluated the scuff resistance of surfaces in regular diesel fuel containing $500 \mathrm{ppm}$ sulfur and in Fischer-Tropsch synthetic diesel fuel containing no sulfur or aromatics. Tests were conducted with the high frequency reciprocating test rig (HFRR) using 52100 steel balls and H-13 tool-steel flats with and without Argonne's special carbon coatings. Test results showed that the sulfur-containing fuels provide about $20 \%$ higher scuffing resistance than does fuel without sulfur. Use of the carbon coating on the flat increased scuffing resistance in both regular and synthetic fuels by about ten times, as measured by the contact severity index at scuffing. Scuffing failure in tests conducted with coated surfaces did not occur until the coating had been removed by the two distinct mechanisms of spalling and wear.
\end{abstract}




\section{INTRODUCTION}

Diesel engines have always been used for heavy-duty applications such as trucks, trains, ships, and off-highway heavy equipment. A major effort is currently underway to use more diesel engines in light-duty applications (instead of gasoline engines) especially in the area of transportation chiefly because of the higher efficiency of diesel engines. This higher efficiency will result in reduced petroleum consumption and of greenhouse gas emission by gasoline-powered automobile engines. A major obstacle to the rapid growth of diesel engines, however, in this application area is the undesirable gaseous emission (primarily oxides of nitrogen, $\mathrm{NO}_{\mathrm{x}}$ ), and particulate emissions produced by diesel engines. Like all engine emissions, these are detrimental to human health and the environment. Consequently, federal and local regulations limit the levels of these emissions. Indeed, much more stringent regulatory limits on these emissions are due to take effect over the next 10 years [1]. Efforts are now being devoted by the diesel engine manufacturers and government agencies to significantly reduce the level of emissions from diesel engines. Several emission control and reduction technologies, such as after-treatment catalysts and exhaust gas recirculation (EGR), are being developed for both light and heavy-duty diesel engines.

It is now clear that the current and impending emission regulations for diesel engines will require diesel fuels with low levels of sulfur and aromatic contents [2-4]. Studies have shown that the rate of particulate emission is directly proportional to the sulfur and aromatic contents of the diesel fuel [3,5]. Furthermore, sulfur in diesel fuel is known to have a detrimental effect on the effectiveness of exhaust emissions control 
systems, primarily after-treatment catalytic devices. Poisoning of the catalyst by sulfur limits the durability and emission reduction capacity of after-treatment devices.

Diesel fuels with low-sulfur and low-aromatic contents are known to have poor lubricity, creating a major technical challenge because the diesel fuel lubricates many components in the fuel delivery systems, such as the fuel pump and fuel injectors. Low lubricity of low-sulfur and low-aromatic diesel fuel is manifested by excessive wear (a durability issue) or catastrophic scuffing failure (a reliability issue) of critical fuel delivery components. Field experience in Sweden and Canada showed a rash of fuel pump and injector failures when diesel fuels with low-sulfur and low-aromatic levels were introduced [6]. The failures were mostly catastrophic and occurred by a scuffing mechanism, resulting in rapid loss of fuel pump performance [7]. Since then, efforts have been made by engine and fuel manufacturers to effectively resolve the problem. It is assumed that the problem may resurface as the sulfur and aromatic levels in diesel fuels are further reduced in order to lower emission levels. Currently, several test methods and standards are being developed to quantify lubricity of diesel fuels. These activities are summarized in a recent review paper by Nikanjam [7].

Component design changes and formulation of diesel fuels with lubricity additives are among the actions being taken to mitigate the problem of poor fuel lubricity and while complying with regulation $s$ to reduce emissions. In addition to low-sulfur and low-aromatic diesel fuels, other measures that can be employed to reduce diesel engine emissions include higher fuel injection pressure and tighter clearance between the injection plunger and the barrel. Both of these will increase the severity of contact and surface interaction between the injector plunger and the barrel. In view of the low 
lubricity of low-sulfur and low-aromatic diesel fuel necessary for low emissions, coupled with the increase in contact severity between fuel delivery components, further enhancement of the surfaces of fuel delivery components is needed to forestall impending reliability and durability problems in low-emission diesel engines.

Various coatings are currently being used to enhance the tribological performance of component surfaces. One class of coating, in its various variations that has attracted much attention over the last decade is the diamondlike carbon coating (DLC). These coatings have unique combinations of properties such as high hardness and modulus, low friction coefficient, and good wear resistance, making them attractive for tribological applications. They are now being used extensively in the magnetic recording industry. Computer hard disks are coated with DLC to prevent catastrophic failure during disc head interaction at startup and shutdown. These coatings are also being used for more severe mechanical interactions such as bearings and gears [8].

Argonne National Laboratory (ANL) recently developed a class of amorphous carbon coatings with excellent friction and wear properties [9-11]. These coatings show very low friction and very low wear under dry sliding contacts, especially in dry nitrogen. Friction coefficients as low as 0.001 and wear rates as low as $10^{-10} \mathrm{~mm}^{3} / \mathrm{Nm}$ have been measured for these coatings under sliding contact. Because of the very low friction coefficient of these coatings, they are designated as "near-frictionless-carbon" (NFC) coatings, and they are very good candidates for the enhancement of diesel engine components that will operate in low-lubricity fuels.

This paper investigates the impact of Argonne's carbon coating on reliabilityreducing scuffing failure mode in diesel engine fuel-system components lubricated by 
diesel fuel. Scuffing is the sudden catastrophic failure of a lubricated contact and is usually accompanied by a sharp rise in friction, contact temperature, noise, and vibration. Scuffed surfaces are severely damaged by plastic deformation and severe wear. In the extreme case, seizure occurs in which the two contact surfaces can no longer slide on each other. Scuffing often occurs early in the life of the component. In low-lubricity fuels, surfaces are very vulnerable to scuffing failure, which has been observed to occur after using less than one tank of fuel [7].

The issue of long-term durability of components in low-lubricity fuels, due to excessive wear, will be investigated later. Accelerated wear failure can take months or years to render fuel injection equipment inoperable.

\section{EXPERIMENTAL DETAILS}

Scuffing tests were conducted with a ball-on-flat configuration in reciprocating sliding contact with a high frequency reciprocating test rig (HFRR). Figure 1 is schematic diagram of the test rig and the contact configuration. The 6.35 -mm-diameter ball specimen are made from hardened and polished 52100 steel with a hardness of about $60 \mathrm{R}_{\mathrm{c}}$ and a surface finish of $0.053 \mu \mathrm{m} \mathrm{Ra}$. The $50 \times 40 \times 10 \mathrm{~mm}$ flat specimens are made of hardened $\mathrm{H}-13$ tool steel with a hardness of $58-60 \mathrm{R}_{\mathrm{c}}$ and a surface finish of $0.035 \mu \mathrm{m} \mathrm{Ra}$. In all tests, the ball specimens were uncoated. Tests were conducted with coated and uncoated flats in standard diesel fuel containing $500 \mathrm{ppm}$ of sulfur and in a synthetic diesel fuel, Fischer-Tropsch (F-T), containing essentially no sulfur or aromatics. 


\section{Coatings:}

NFC coating was deposited on $50 \times 40 \times 10 \mathrm{~mm}$ steel flat test samples and with RFplasma-assisted chemical vapor deposition (PACVD) method. The surfaces to be coated were first sputter-cleaned in Ar plasma for $30 \mathrm{~min}$. This was followed by sputtering deposition of a 50-70-nm-thick Si bond layer. The sputter cleaning and deposition of the Si bond layer ensured good adhesion between the NFC coating and the substrate steel material. A proprietary mixture of gas was then blended into the chamber to create the plasma for chemical vapor deposition of the NFC coating. A coating thickness of about $1.5 \mu \mathrm{m}$ was deposited on the flat specimen.

\section{Diesel Fuels:}

Table 1 shows some of the pertinent properties of the two diesel fuels evaluated. The standard fuel contains a significant amount of sulfur and aromatics. Diesel engines operating with this fuel are expected to emit perhaps higher than regulatory levels of emissions. Because of the relatively high level of sulfur in the fuel, poisoning of aftertreatment device catalyst is also expected. The fuel, however, has adequate lubricity to protect the injector and fuel pump components against catastrophic failure and accelerated wear. The second diesel fuel (F-T) is synthetic with essentially no sulfur and no aromatics. Tests have shown that this fuel will indeed reduce the level of diesel engine emissions and will not compromise the effectiveness and durability of aftertreatment catalysts. However, the lubricity of this fuel is very poor, in terms of scuffing and wear protection. It cannot be used in diesel engines without "re-formulation" with 
lubricity-enhancing additives. The full impact of such additives on emissions and aftertreatment catalysts has not been fully assessed.

Table 1: Properties of test diesel fuels

\begin{tabular}{llc} 
Property & Regular diesel fuel & Fischer-Tropsch \\
Specific gravity & 0.84 & 0.77 \\
Viscosity at $40^{\circ} \mathrm{C}(\mathrm{cSt})$ & 2.45 & 2.10 \\
Sulfur content (ppm) & 500 & $<3$ \\
Aromatic content $(\%)$ & 24 & $<2$ \\
Pressure viscosity coefficient $(\alpha)$ & $8.3\left(\mathrm{GPa}^{-1}\right)$ & $8.0\left(\mathrm{GPa}^{-1}\right)$ \\
\hline
\end{tabular}

\section{Scuffing Test Procedure:}

Different test protocols can be used to induce scuffing failure. The most common is the step-loading test in which the contact load is increased in pre-determined discrete steps and duration until scuffing occurs, while all other test variables are held constant. Scuffing resistance is judged by the contact load required to cause scuffing failure. There is also the step-speed-increase protocol in which sliding speed is progressively increased in predetermined discrete stages until scuffing occurs; scuff resistance is judged by the speed which at scuffing occurs. Scuffing can also be induced by lubricant starvation, whereby the supply of lubricant to the contact interface is interrupted. Scuff resistance is judged by the time required for scuffing to occur once no lubricant is 
supplied to the contact interface. Scuffing can also be induced by progressive increases in test temperatures. Scuffing resistance is determined by the temperature at scuffing.

All of these scuffing test protocols have one thing in common: they involve a the progressive increase in the severity of contact and interaction between the test surfaces until scuffing occurs. Perhaps it would be more appropriate to judge the propensity of test surfaces to scuffing by the degree of contact severity required to initiate scuffing. A good measure of severity of contact between two surfaces in sliding contact is the socalled frictional power, which is the product of friction coefficients, contact load, and sliding speed. This parameter would be a better measure of scuffing resistance and could be used to compare the scuffing attributes of the various test combinations in this study. It should be noted that there is a scuffing criterion based on this parameter: it has been suggested that scuffing occurs when the frictional power reaches a critical value $[12,13]$. There are several other scuffing criteria, including critical contact temperature, critical flash temperature, critical frictional power intensity, EHD and micro-EHD film breakdown, thermoelastic instability, and many others. Details of these criteria have been reviewed in many papers over the years [e.g., 14-16], but none have been adequate in predicting scuffing, largely because the basic mechanisms of scuffing are still not fully understood. Our goal in the present study is not to validate or disprove the critical frictional power criteria for scuffing, but rather to "quantify" the severity of contact at scuffing. Therefore, we have designated this parameter (i.e. the product of friction coefficient, load, and speed) as the contact severity index (CSI). The higher the contact severity index, the better the scuffing resistance of tested surface and lubricant combinations. This parameter will be used as a measure of scuff resistance. 
In the present study, scuffing tests were conducted at different constant contact loads and with a step-increases in sliding speed until scuffing occurred. Tests were conducted in the load range of $150-400 \mathrm{~N}$, corresponding to initial Hertzian stress of 1.1$1.8 \mathrm{GPa}, 1-15 \mathrm{~Hz}$ reciprocating frequency, and a stroke length of about $20 \mathrm{~mm}$, translating to a sliding speed in the range of $0.04-0.6 \mathrm{~m} / \mathrm{s}$. All tests were conducted under ambient room conditions of about $25^{\circ} \mathrm{C}$ and relative humidity of $20-25 \%$. The contact interface was fully flooded by the test diesel fuel by submerging the flat specimens in a lubricant cup filled with the test fuel. Each test for a given constant load was started with a sliding speed of $0.04 \mathrm{~m} / \mathrm{s}$. The speed was increased in a step of 0.04 $\mathrm{m} / \mathrm{sec}$ every 2 min until scuffing occurred or until the maximum speed of $0.6 \mathrm{~m} / \mathrm{s}$ was reached, at which point a run-out is declared. The friction coefficient was continuously monitored and recorded during each test.

Scuffing tests were conducted with an uncoated flat and Agonne's NFC coated flat in regular diesel fuel and synthetic F-T diesel fuel. Repeated tests were conducted for the various test combinations. At the conclusion of each test, optical and scanning electron microscopes (SEM) were used to characterize the failure mode on the test sample surfaces.

\section{TEST RESULTS}

Figure 2 shows the variation of the friction coefficients with time during the scuffing test with an uncoated ball sliding against an uncoated flat. The effect of the better lubricity of the regular diesel fuel (with $500 \mathrm{ppm} \mathrm{S}$ ) is clearly apparent. No scuffing failure was observed in tests up to loads of $210 \mathrm{~N}$ (Figure 2a). However, at 230 
$\mathrm{N}$ load, scuffing occurred during the first speed-step. The frictional behaviors in all the tests that did not scuff were very similar to one another. There was a period of run-in during which the friction coefficient decreased from an initial value of $\approx 0.18$ to $\approx 0.1$. In tests with the synthetic F-T diesel, scuffing occurred in all tests, even at the low load of $150 \mathrm{~N}$ (Figure $2 \mathrm{~b}$ ). Frictional behavior with the F-T fuel also showed run-in characteristics, whereby the friction coefficient decreased from $\approx 0.16$ to $\approx 0.09$ just before scuffing. At the scuffing point, the friction coefficient suddenly increased rapidly as expected (Figure $2 \mathrm{~b}$ ). At a load of $180 \mathrm{~N}$, scuffing occurred during the first speed step. For the uncoated surface, it is clear that scuffing resistance in regular diesel fuel is higher than that in the synthetic fuel. In view of the stochastic nature of scuffing failure, repeatability of the tests was very good. Figure 3 shows the friction trend in two repeat tests for uncoated contact pairs at $200 \mathrm{~N}$ in regular diesel fuel. Except for the period between 1100 and $1300 \mathrm{sec}$, the friction behavior for both tests was nearly identical. Both tests ran-out without scuffing.

Figure 4 shows the frictional behavior of tests conducted with coated flat specimens. With regular diesel fuel, tests up to $350 \mathrm{~N}$ load all ran-out without scuffing (Figure 4a). At higher loads of 375 and $400 \mathrm{~N}$, scuffing occurred. In tests with this fuel at all loads, microscuffing occurred as indicated by the periodic spikes in the friction trace. Microscuffs are small localized areas of severe damage within the contact area, but that do not progress to massive catastrophic failure. Such microscuffs are often "healed" over and the surface remains functional. In this same fuel, the friction coefficient was nearly steady for the duration of test. In the tests with the F-T synthetic 
fuel, scuffing occurred at the three test loads evaluated (Figure 4b), and there was no microscuffing. Some run-in occurred, with a slight decrease of friction coefficient.

Although the NFC coating did not change the frictional behavior significantly in either the regular or synthetic diesel fuel (compare Figures $2 a$ and $4 a ; 2 b$ and $4 b$ ), it had a major impact on scuffing resistance in both fuels. Ignoring the run-out data, Table 2 summarizes the estimated contact severity index at scuffing; the same data are shown in Figure 5. The NFC coating significantly improved scuffing resistance by a factor of about 10. Sulfur content also had a noticeable effect on scuffing resistance. When both surfaces are uncoated, there were many run-outs with regular fuel containing sulfur, while all the tests with F-T fuel with no-sulfur failed. For the scuffed test only, the average contact severity index with high sulfur is about $20 \%$ higher than that of synthetic fuel, and that is ignoring the many run-out tests in regular fuel.

Table 2: Average Contact Severity Index at Scuffing

\begin{tabular}{|c|c|c|}
\hline Test Flat & Regular Fuel & Synthetic F-T Fuel \\
\hline Uncoated & 1.132 & 0.964 \\
\hline NFC-Coated & 8.646 & 9.992 \\
\hline
\end{tabular}

Microscopic analysis of the tested surfaces provided some information on the differences in the behavior of coated and uncoated surfaces during the scuffing tests. For the uncoated surface, a typical scuffed surface is shown in Figure 6. There is severe damage in the form of plastic deformation and material loss; this is the typical appearance of a scuffed surface. The damage features on scuffed surfaces in the regular and 
synthetic F-T diesel fuels are very similar to each other and are typified by Figure 6. Figure 7 shows the typical appearance of a wear track in tests that ran-out without scuffing on the uncoated surface in the regular diesel fuel. There is evidence of some mild abrasive wear. Chemical analysis by X-ray energy dispersive spectroscopy (EDAX) also showed that the sulfur level in the wear track is about 2.25 atomic wt. \% compared to 1.22 for areas outside the contact area. This suggests there was preferential reaction of sulfur, from the fuel, with the specimen surface during the scuffing test.

In the tests conducted with NFC-coated flats, scuffing occurred only after the coatings had been worn away or otherwise removed (Figure 8). This was the case in the tests with regular and synthetic fuels. Once the coating was gone, the scuffing damage in the steel substrate was similar to that of the uncoated specimens (compare Figures 9 and 6). In many of the tests with coating that ran-out without scuffing in the high-sulfur fuel, the coatings had been completely removed except for tiny patches, as shown in Figure 10. In such cases, wear track damage after coating removal consisted of general polishing or mild wear.

Coating removal occurred by gradual wear in some tests (Figure 11). Evidences of cracking and coating spalling was also observed (Figure 12). As expected, coating cracking and spalling are more prevalent in the tests conducted at higher contact loads. The cracks were observed in both scuffed and unscuffed tests, and thus were not initiated or caused by the scuffing process. Crack formation is caused by the inability of the hard and brittle coating to accommodate the imposed contact stresses at the interface by plastic flow, as metals do. 


\section{DISCUSSIONS}

Results of the present study showed clearly that the ultra-low-sulfur and lowaromatic fuels that will be required to reduce emissions in diesel engines to levels compliant with impending regulations will also make steel component surfaces that are lubricated by the fuel vulnerable to scuffing failure. In this study, the uncoated surface showed much higher scuffing resistance in the regular diesel fuel with high-sulfur than in the no-sulfur synthetic F-T diesel fuel. There are two possible mechanisms for this difference, and there may be some synergy between the two mechanisms.

First, the viscosity of the regular fuel containing sulfur and aromatics was slightly higher than that of the synthetic fuel with no sulfur and low aromatics. An earlier study by Wang $[17,18]$ showed that diesel fuel lubricity is dependent on fuel viscosity and aromatic content. As Table 1 indicates, there are significant differences in the viscosity and aromatic levels of the two fuels. It is also known that the efficacy of fluid-film lubrication is dependent on lubricant viscosity to some extent. The EHD fluid film thickness (h) formed by the two fuels can be estimated by [19]

$$
\mathrm{h} \alpha\left(\mathrm{U} \eta_{\mathrm{o}}\right)^{0.67} \alpha^{0.53}
$$

where $U$ is the entraining velocity, $\eta_{\mathrm{o}}$ is the dynamic viscosity at atmospheric pressure, and $\alpha$ is the pressure viscosity coefficient. Using the fuel properties in Table 1, we estimated EHD film thickness for regular fuel to be about $3.3 \mathrm{~nm}$, and that of synthetic fuel to be about $2.7 \mathrm{~nm}$, both at the maximum speed of $0.5 \mathrm{~m} / \mathrm{s}$. According to the loadshare model of lubrication, a thicker lubricant fluid film will reduce the load carried by surface asperities and hence the severity of interaction between the surfaces in contact. 
Thus, in the present study, the thicker film of the regular fuel will result in less severe interactions between the surfaces, thereby providing more protection against scuffing.

Second, surface chemical analysis show the possibility of sulfur reaction with the surface during testing with sulfur-containing regular diesel fuel. Sulfur and sulfur compounds are known to be strong extreme pressure (EP) additives that can protect steel surfaces against scuffing failure. In diesel fuel, sulfur has been observed to be pro-wear [20], but the present study shows that it does provide protection against scuffing.

The NFC coating provided significant protection for the steel surfaces against scuffing failure. The scuffing resistance of coated surfaces in terms of contact severity index is about 10 times that of uncoated surfaces. This was the case for both sulfurcontaining regular and no sulfur synthetic F-T diesel fuels. In all tests with coated surfaces, scuffing occurred only after the coating has been worn away or otherwise removed, possibly because the coating surface cannot undergo massive plastic flow, which is required for scuffing to occur. The higher hardness of the coating makes it much more resistant to plastic deformation than is the steel surface.

Coating removal from the steel surface during the tests occurred by two mechanisms, namely wear and spalling. Microscopic evidence showed that in some tests, the coating layer was gradual worn away. There were also evidence of cracking and spalling of the coating. Once the coating was removed, scuffing of the steel substrate occurred by severe plasticity and surface damage. However, coating removal did not always result in scuffing. In several tests that ran out, the coating was already removed but scuffing did not occur. Thus, removal of the NFC coating from the steel surface is a necessary but not sufficient condition for scuffing. Based on the two observed failure 
mechanisms for the coating, two possible ways to further enhance the performance of the NFC coatings in terms of scuffing protection for steel surfaces are increased coating adhesion (to prevent spalling) and lower wear rate.

This study clearly identifies an effective means of solving the reliability problem of catastrophic failure due to scuffing in fuel injection system of diesel engines operating with low-sulfur and low-aromatic fuels. The use of Argonne's NFC coating improves the scuffing resistance of steel surfaces operating in no-sulfur fuel about 10 times over the regular sulfur-containing fuel. As a result of the low lubricity of the no-sulfur fuels, early catastrophic failure of fuel pumps and injectors have been encountered. The use of carbon coatings on the critical component will solve the problem of such failure with low lubricity diesel fuel. Use of the coating is a more attractive option than addition of lubricity additives to the fuel. This is because little is known about the effect of such additives on emissions. Another manifestation of the low lubricity of no-sulfur diesel fuel is accelerated wear, which compromises the durability of the fuel injection system. Plans are underway to evaluate the impact of the NFC coating on wear and hence durability.

\section{CONCLUSIONS}

Scuffing resistance of uncoated and Argonne's near-frictionless carbon (NFC)coated steel surfaces was evaluated in regular diesel fuel and in no-sulfur and lowaromatic synthetic diesel fuel. The no-sulfur and low-aromatic synthetic fuel showed poor lubricity in terms of low scuffing resistance. This poor lubricity creates reliability and durability problem for diesel engine fuel injection systems. Use of the NFC coating 
increased the scuffing resistance by a factor of more than 10 , as measured by contact severity index. This coating is an effective practical means of preventing catastrophic failure by scuffing in low-lubricity diesel fuels. It is a more attractive option than the use of lubricity-enhancing additives in diesel fuels, because the effects of such additives on emissions are still unknown.

\section{ACKNOWLEDGMENT}

This work was supported by the U.S. Department of Energy, Office of Transportation Technologies under contract W-31-109-Eng-38.

\section{REFERENCES}

1. Walsh M. P., 1998, "Global trends in Diesel Emissions Contact: A 1998 Update," SAE Tech. Paper 980186.

2. Li X.B., Chippior W.L., and Gulder O.L., 1996, "Effect of Fuel Properties on Exhaust Emissions of a Single Cylinder DI Diesel Engine," SAE Tech. Paper 962116.

3. Large W.W., 1991, "The Effect of Fuel Properties on Particulate Emission in Heavy-Duty Truck Engines under Transient Operating Conditions," SAE Tech. Paper 912425.

4. Mitchell K. Steeve D.E., Taylor J.A., Manicom B., Fisher J.E., Sienicki E.J., Chin C., and Williams P., 1994, "Impact of Diesel Fuel Aromatics on Particulate, PAH and Nitro-PAH Emissions," SAE Tech. Paper 942053.

5. Wall J.C., and Hochman S.K., 1984, "Fuel Consumption Effects on Heavy-Duty Diesel Particulate Emissions," SAE Tech. Paper 841264. 
6. Caprotti R., Borington C., Fowler W., and Taylor M., 1992, "Additive Technology as a Way to Improve Diesel Fuel Quality," SAE Tech. Paper 922183.

7. Nikanjam M., 1999, "Diesel Fuel Lubricity: on the Path to Specifications" SAE Tech. Paper 1999-01-1479.

8. Lifshitz Y., 1999, "Diamond-Like Carbon-Present Status," Diamond Rel. Mater., 8, pp.1659-1676.

9. Erdemir A., Bindal C., Fenske G.R., and Wilbur, 1996, "Tribological Properties of Hard Carbon Film on Zirconia Ceramics," STLE Trib. Trans., 39, 735-744.

10. Erdemir A., Fenske G.R., Terry J., and Wilbur P., 1997, "Effect of Source Gas and Deposition of Diamond-Like Carbon Films," Surf. Coat. Tech., 94-97, 525-530.

11. Erdemir A., Nilufer I. B., Eryilmaz, Beschliesser M., and Fenske, G. R., 1999, "Friction and Wear Performance of Diamond-Like Carbon Films Grown in Various Gas Plasmas," Surf. Coat. Tech., 120-121, 589-593.

12. Horng J.H., 1998, "True Frictional Power Intensity and Scuffing in Sliding Contacts," ASME J. of Trib., 120, 829-834.

13. Meng V.V., 1960, "The Investigation of Steel Seizure with Disc Machine," Friction and Wear of Machines, 14, 222-237.

14. Dyson A., 1975, "Scuffing-A Review, Part 1 and 2", Tribol. Int., 8, 77-87; 117-122.

15. Ludema, K. C., 1984, "A Review of Scuffing and Running-in of Lubricated Surfaces with Asperities and Oxides in Perspective", Wear, 100, 315-331.

16. Park, K. B. and Ludema, K. C., 1994, "Evaluation of the Plasticity Index as a Scuffing Criterion", Wear, 175, 123-131. 
17. Wang, J. C. and Reynolds, D. J., 1994, "The Lubricity Requirement of Low Sulfur Diesel Fuels", SAE Tech. Paper, 942015.

18. Wang, J. C. and Cusano, C. M., 1995, "Predicting Lubricity of Low Sulfur Diesel Fuel", SAE Tech. Paper, 952564.

19. Wei, D. P., Spikes, H. A., and Korcek S., 1999, "The Lubricity of Gasoline", STLE Trib. Trans., 42, 813-823.

20. Wei, D. P., and Spikes, H. A., 1986, "The Lubricity of Diesel Fuels," Wear, 111, $217-235$. 


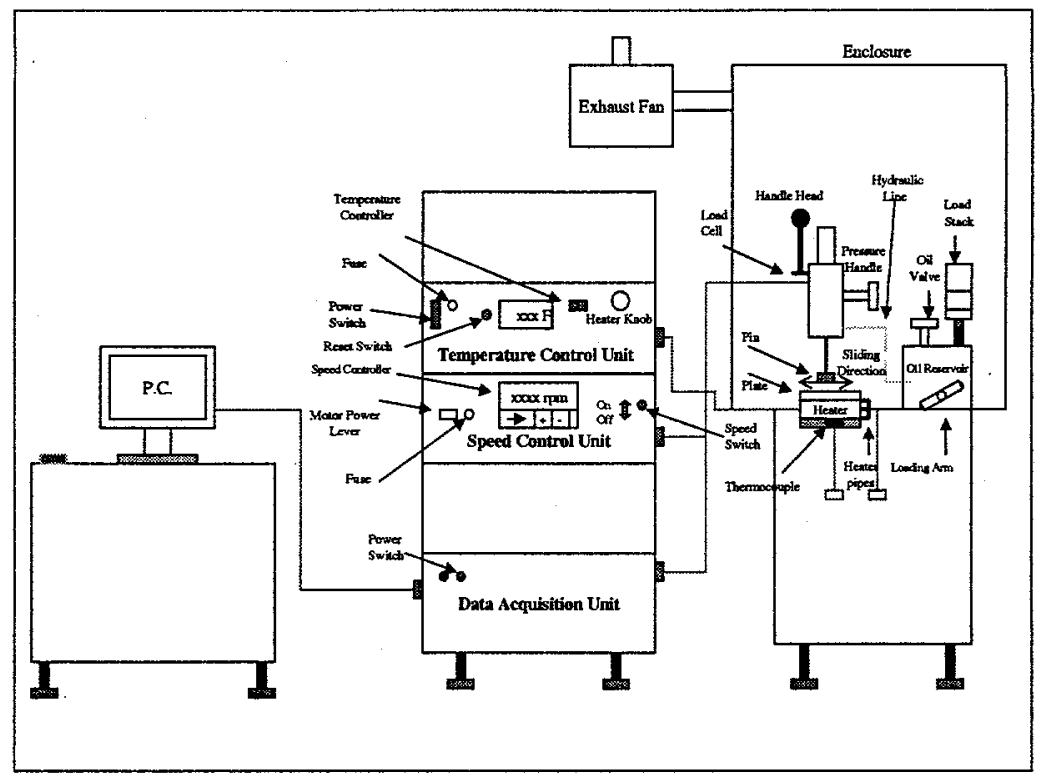

Figure 1a: Schematic diagram of friction and wear test rig.

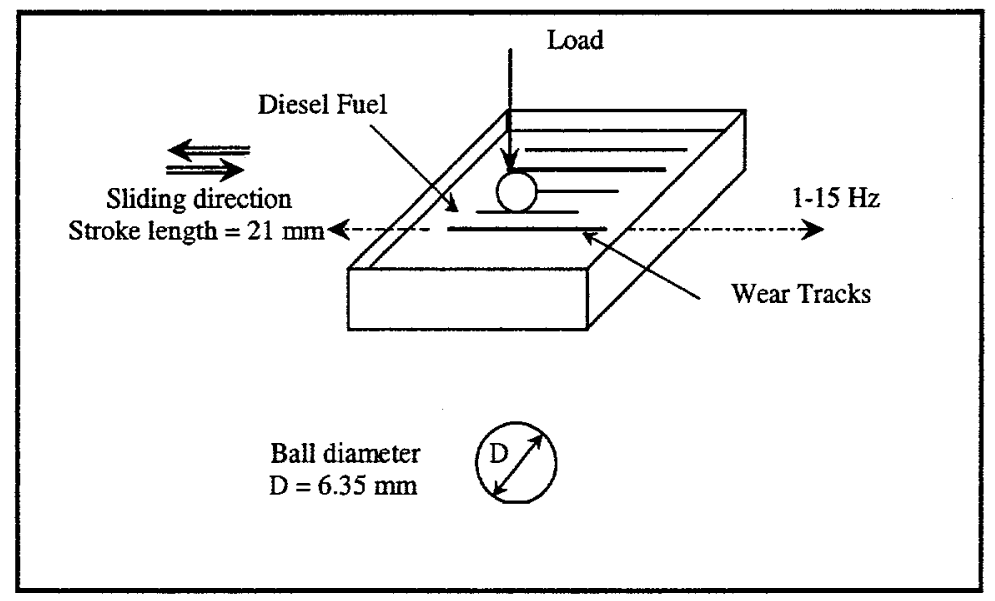

Figure 1b: Schematic diagram of ball-on-flat contact configuration 


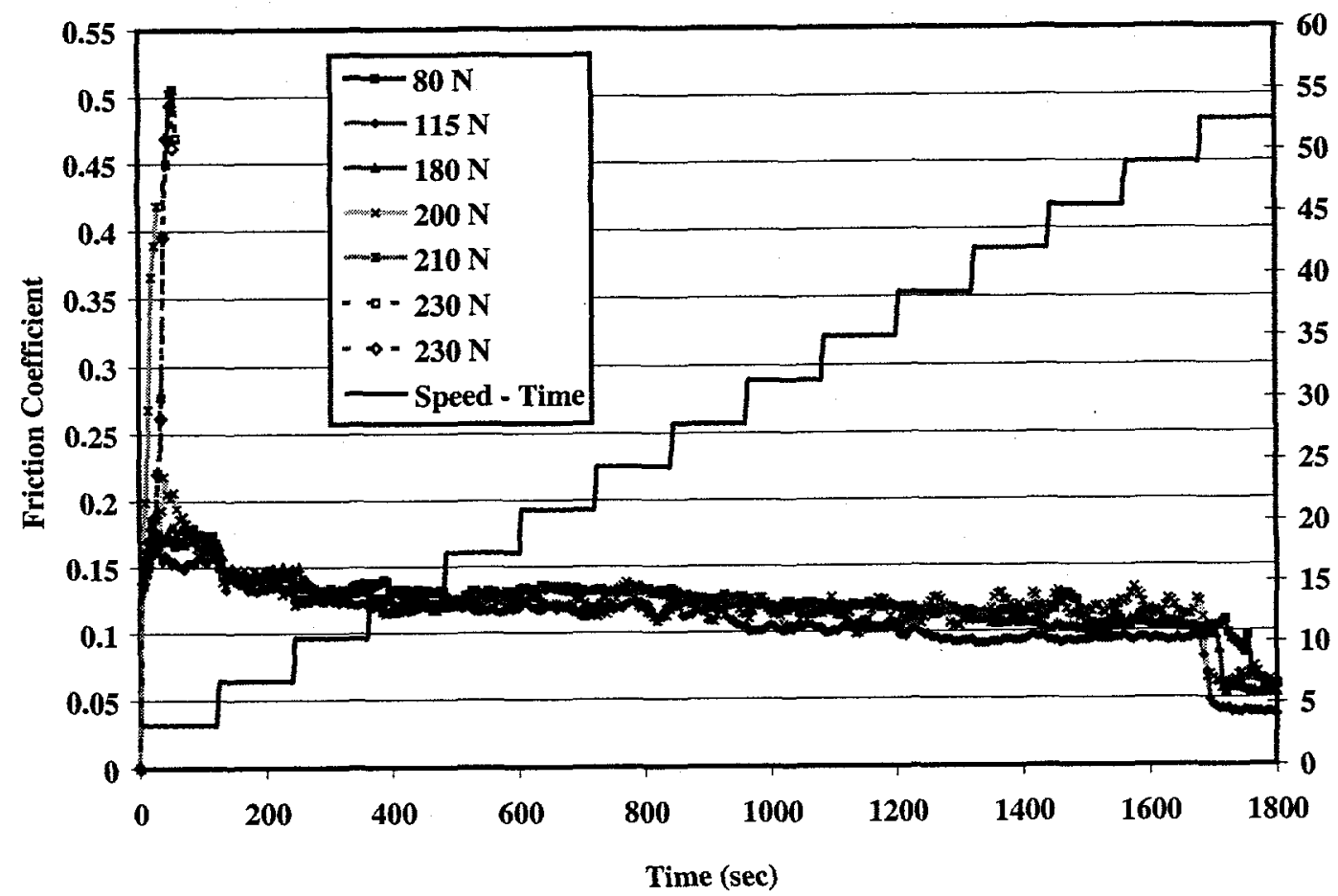

Figure 2a. Friction coefficient variation with time in tests with uncoated flat in regular diesel fuel

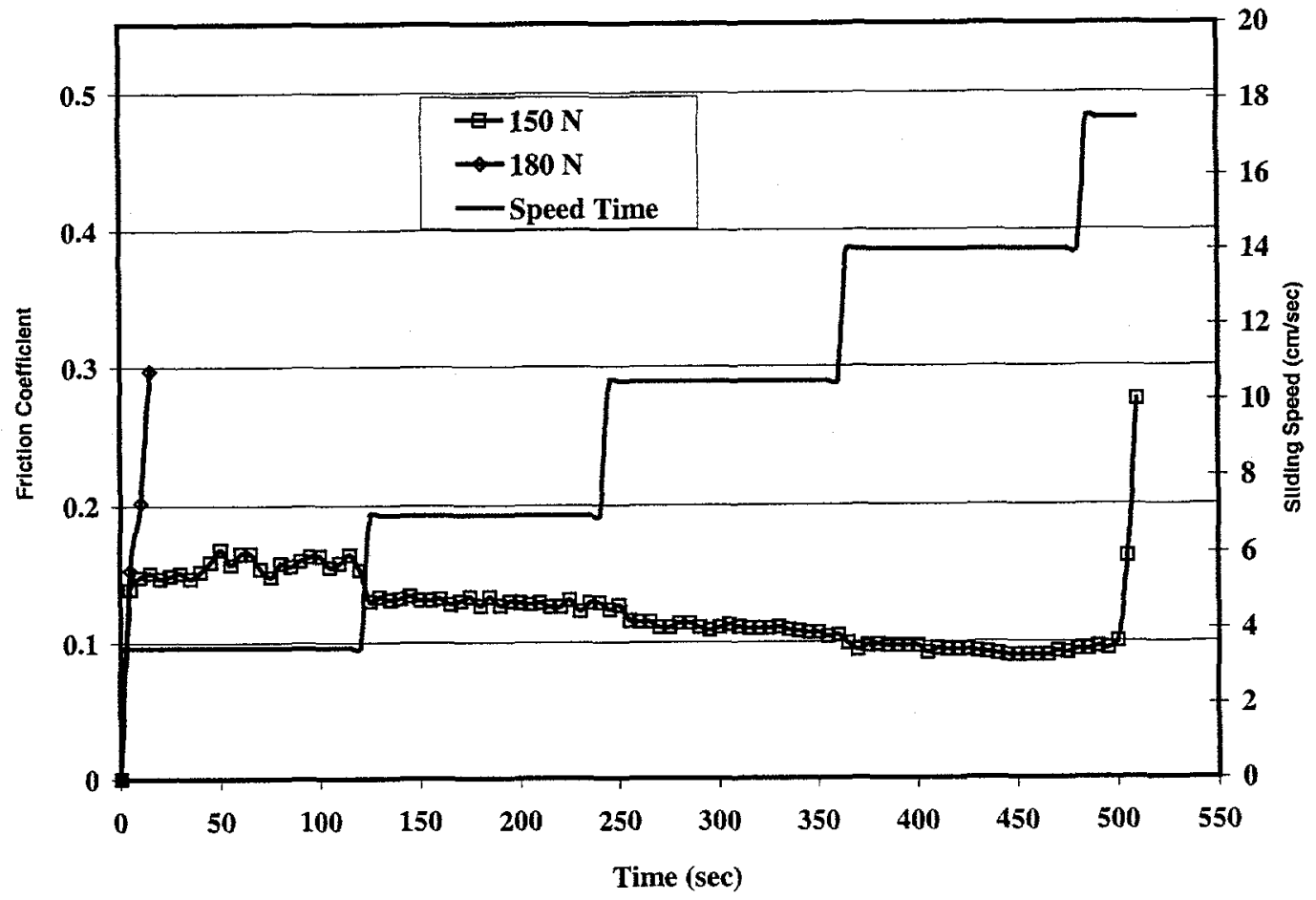

Figure 2b: Friction coefficient variation with time for uncoated flat in synthetic $F-T$ diesel fuel 


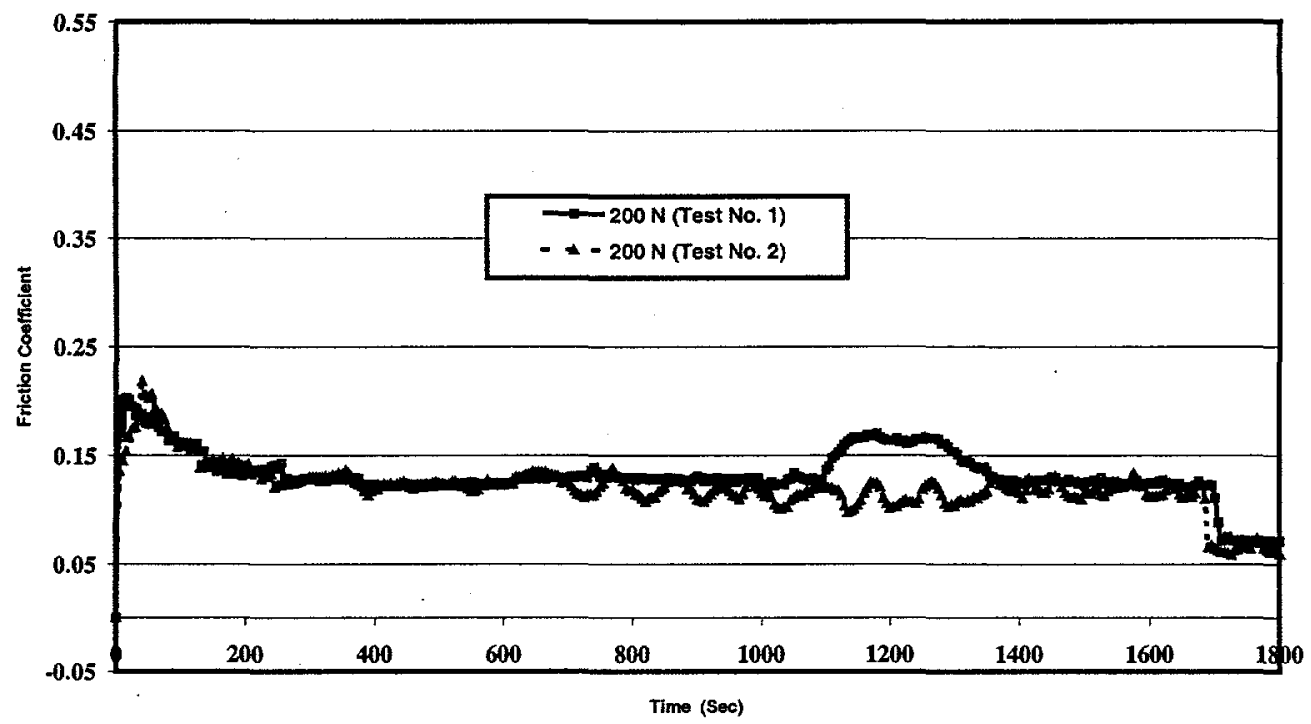

Figure 3: Friction coefficient vs. time in repeat test with uncoated flat in regular

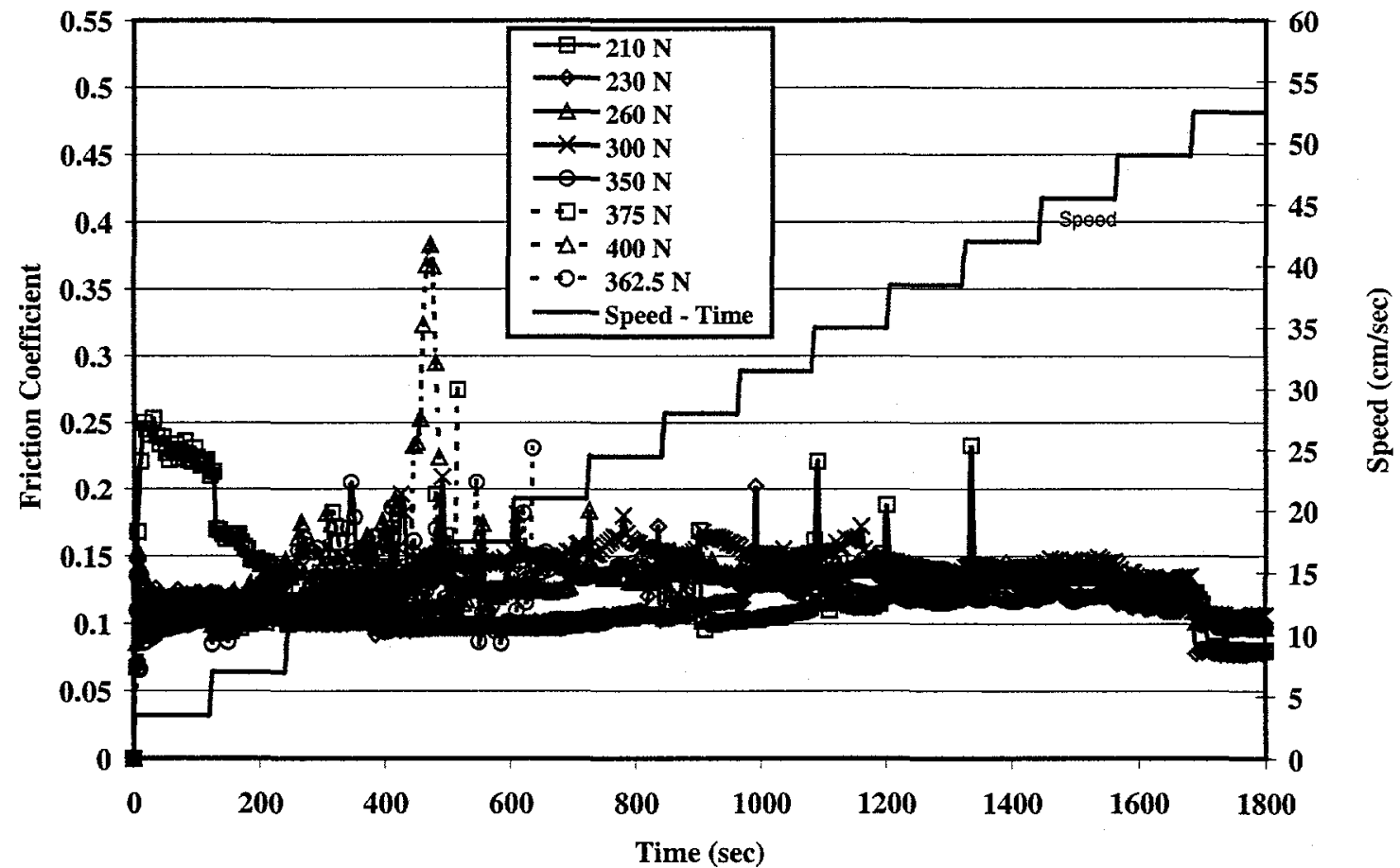

Figure 4a. Friction coefficient variation with time for NFC-coated flat in regular diesel fuel 


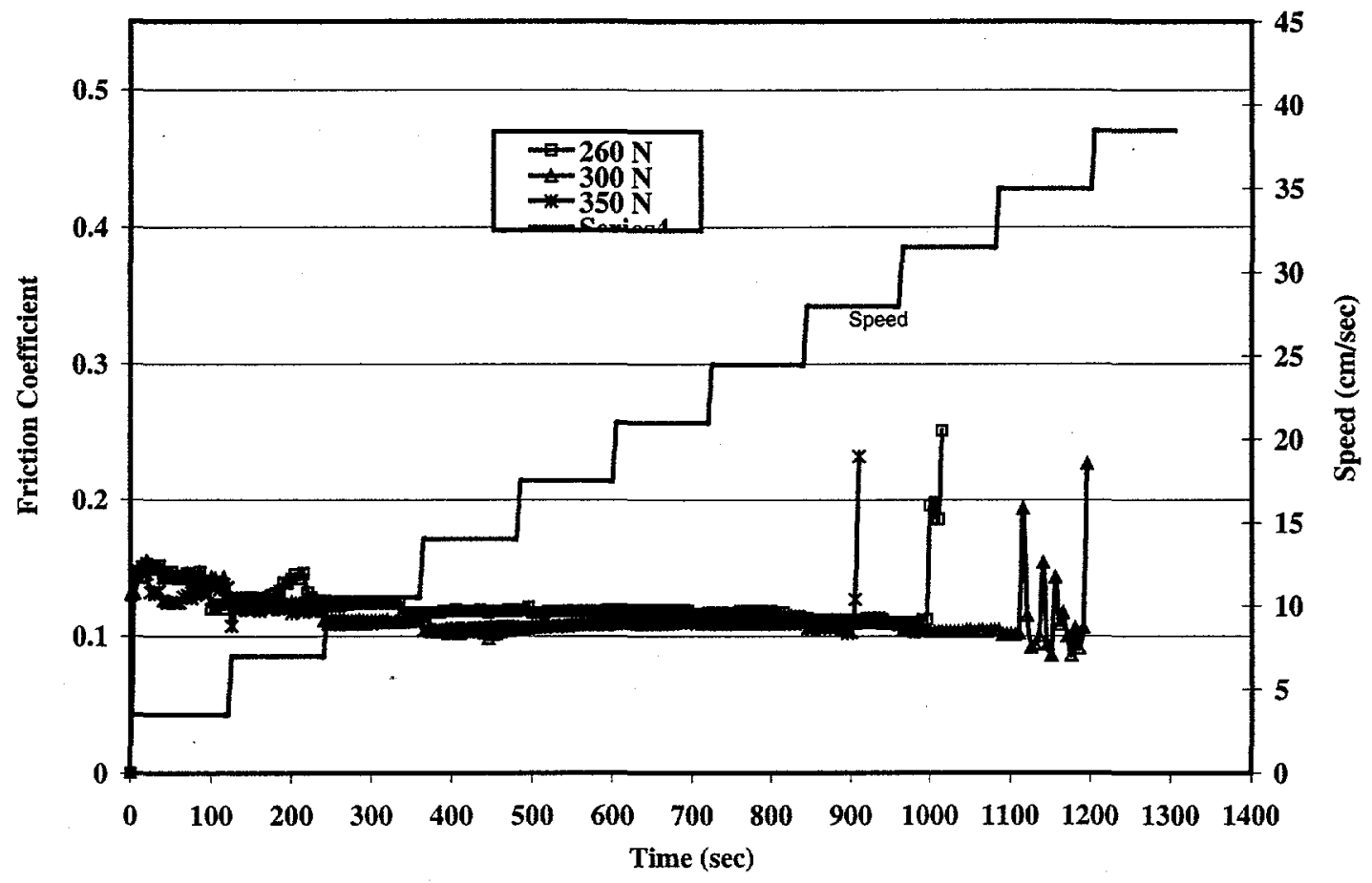

Figure 4b: Friction coefficient variation for tests with NFC-coated flat in synthetic F-T diesel fuel

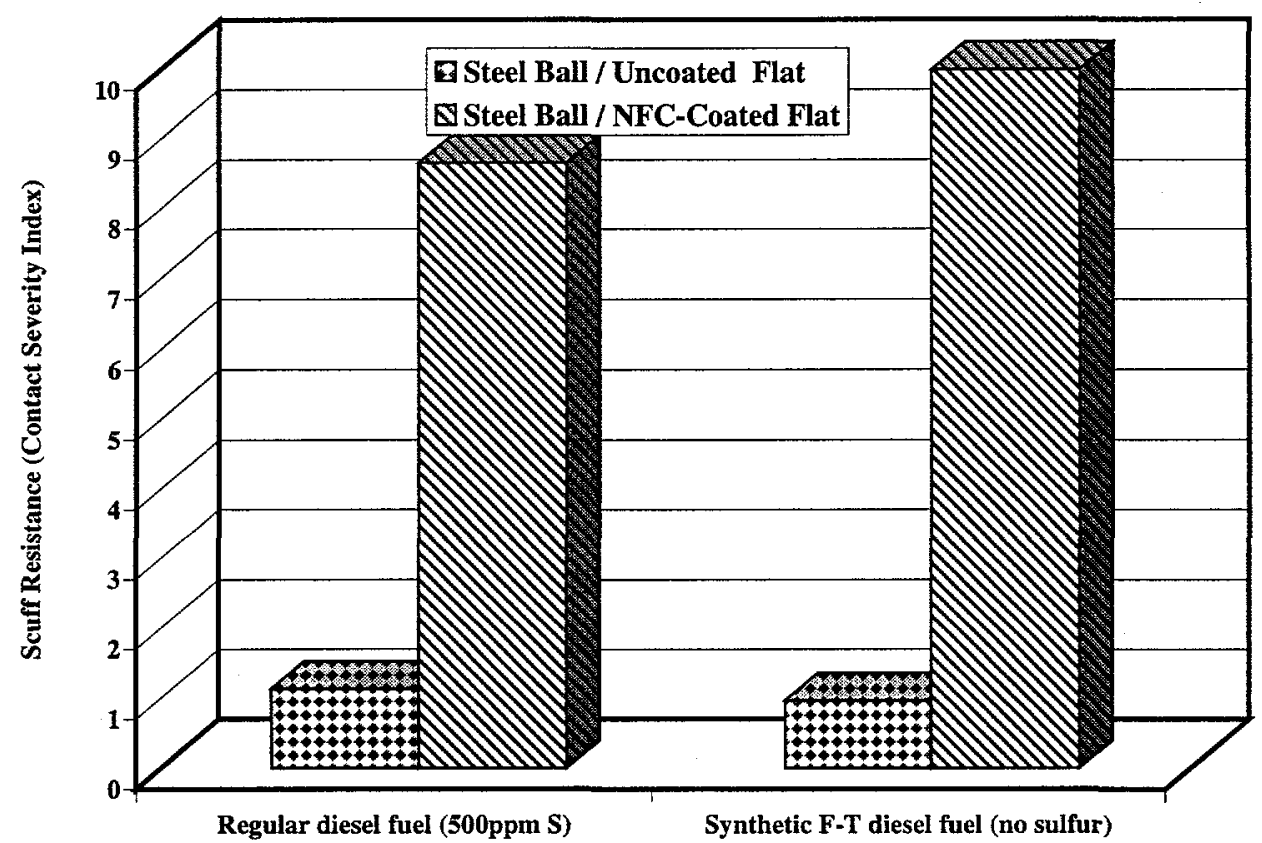

Figure 5: Average contact severity index in tests with regular and synthetic diesel fuels 


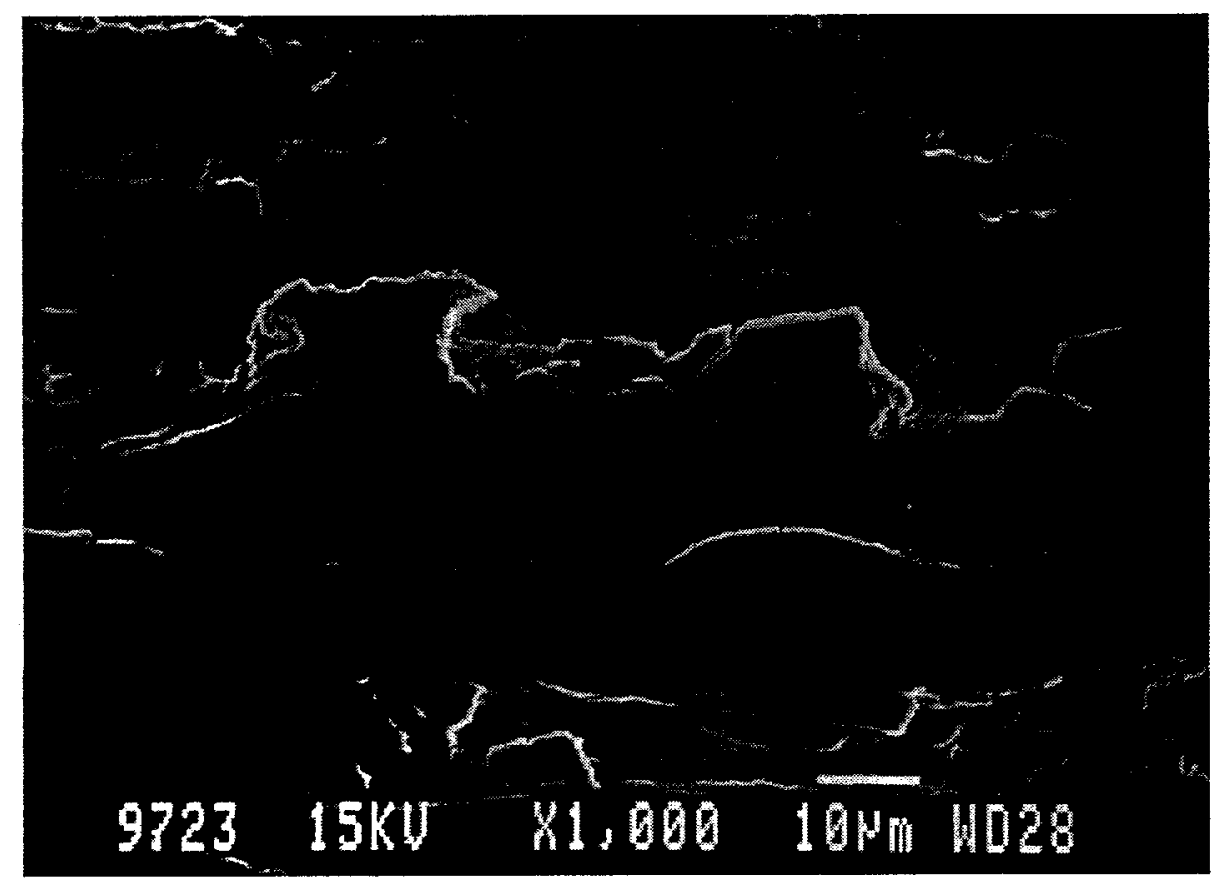

Figure 6: SEM photomicrograph of typical scuffed uncoated flat surface.

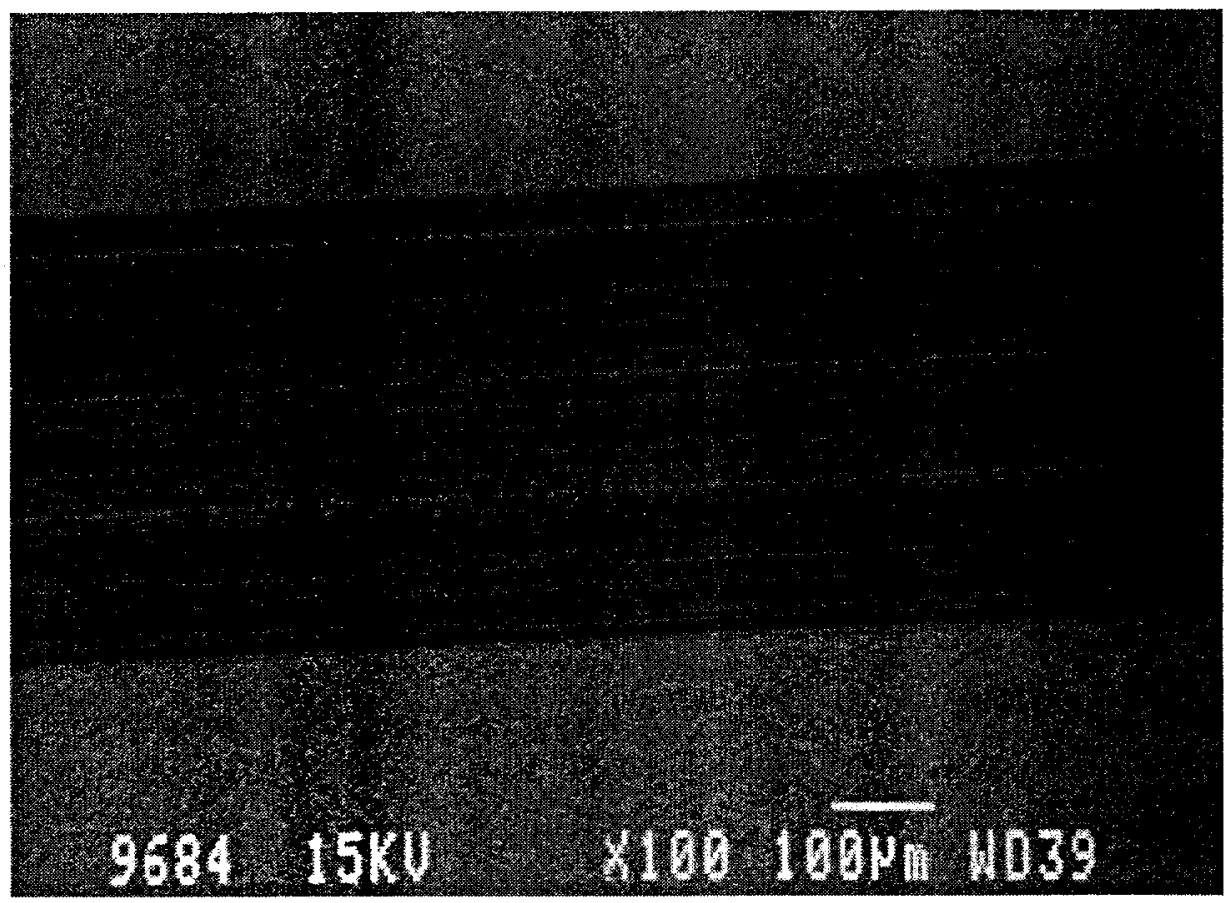

Figure 7a: Wear track on uncoated flat specimen surface tested in regular diesel fuel without scuffing 
M-unscur- 45

flat 99-951

$9581 \quad 15 \mathrm{KV}$

\section{X500 $10 \mu_{\text {in }} \quad 4039$}

Figure 7b: Wear track on uncoated flat specimen surface tested in regular diesel fuel without scuffing

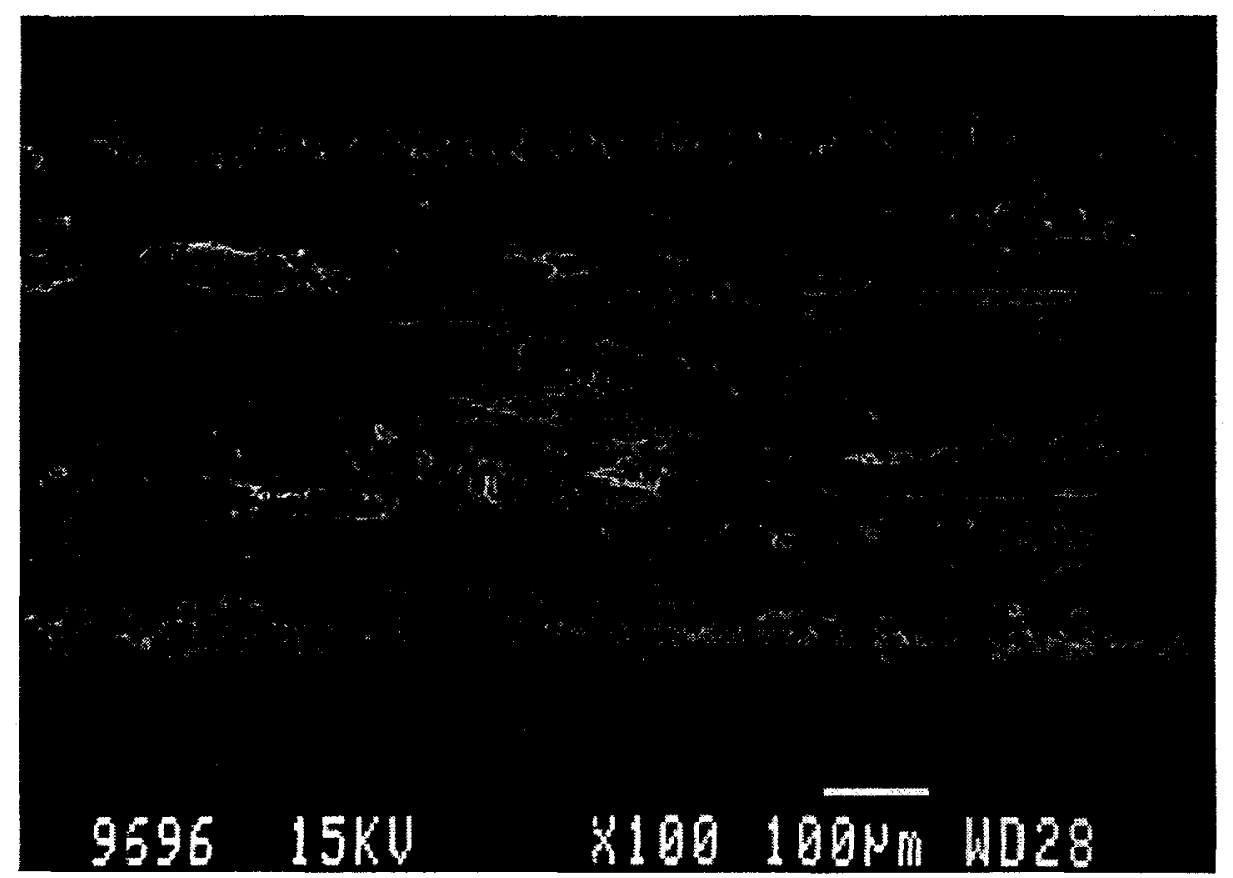

Figure 8: Track on coated surface tested with synthetic F-T diesel fuel. 


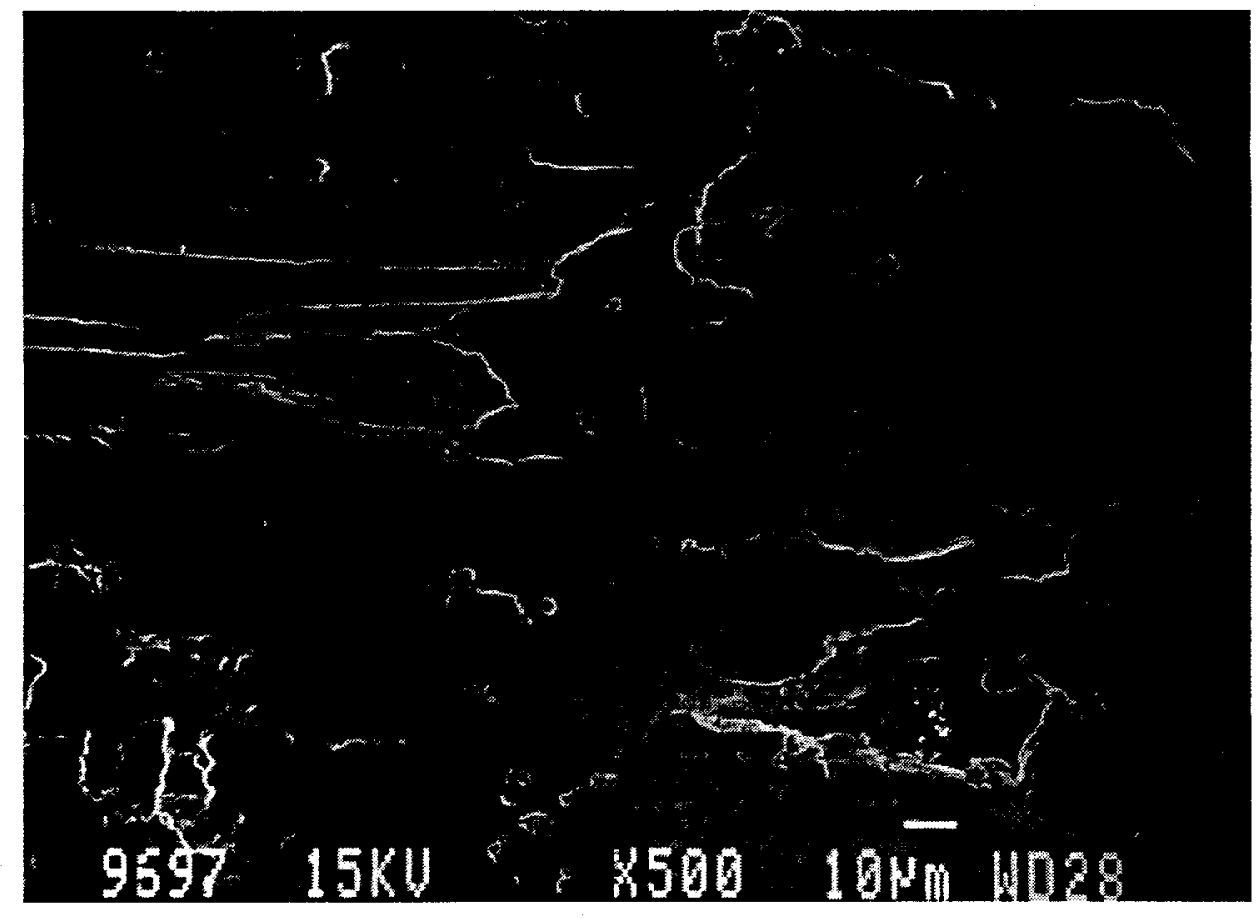

Figure 9: Scuffed surface of coated flat after removal of coating

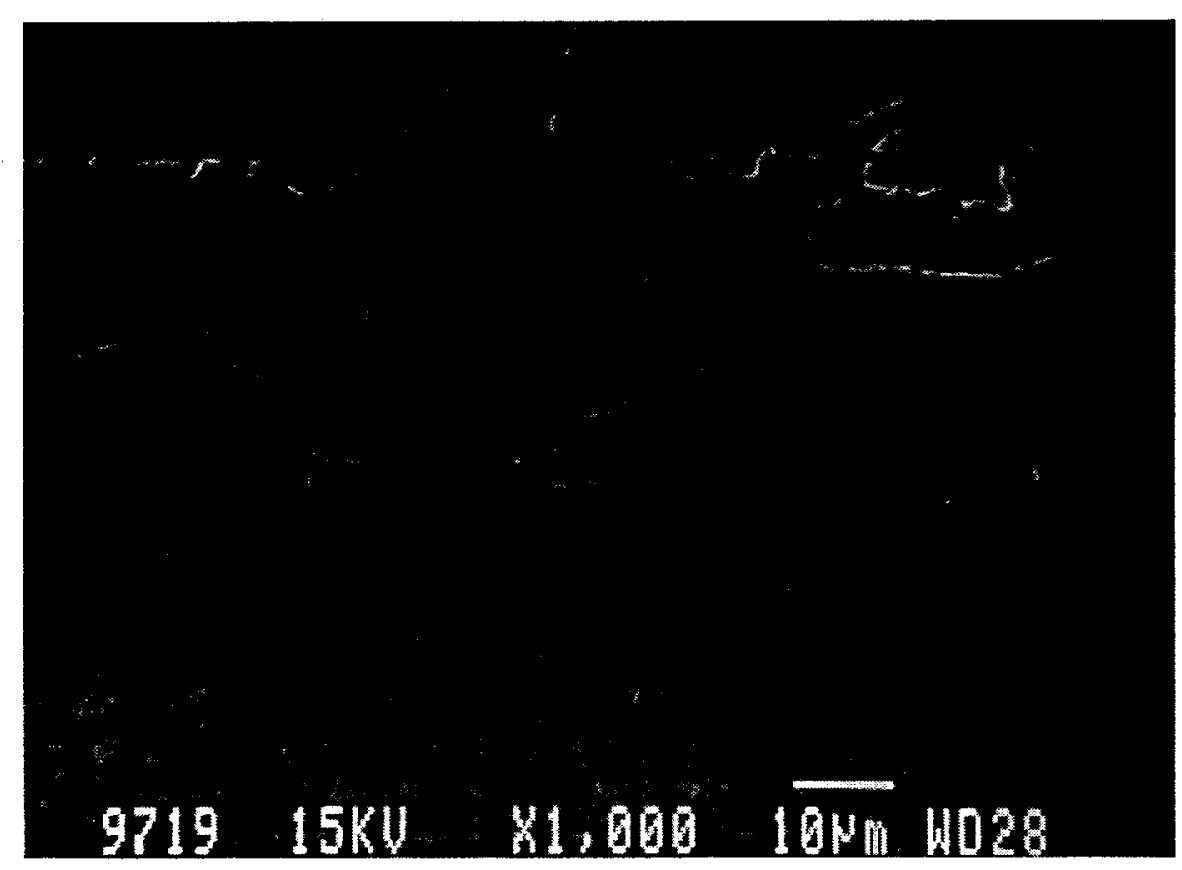

Figure 10: Coating removal (except for few patches) without scuffing 


\section{15KU K1,000 10\% HD28}

Figure 11: Edge of track on coated flat showing gradual wear as mechanism for coating removal.

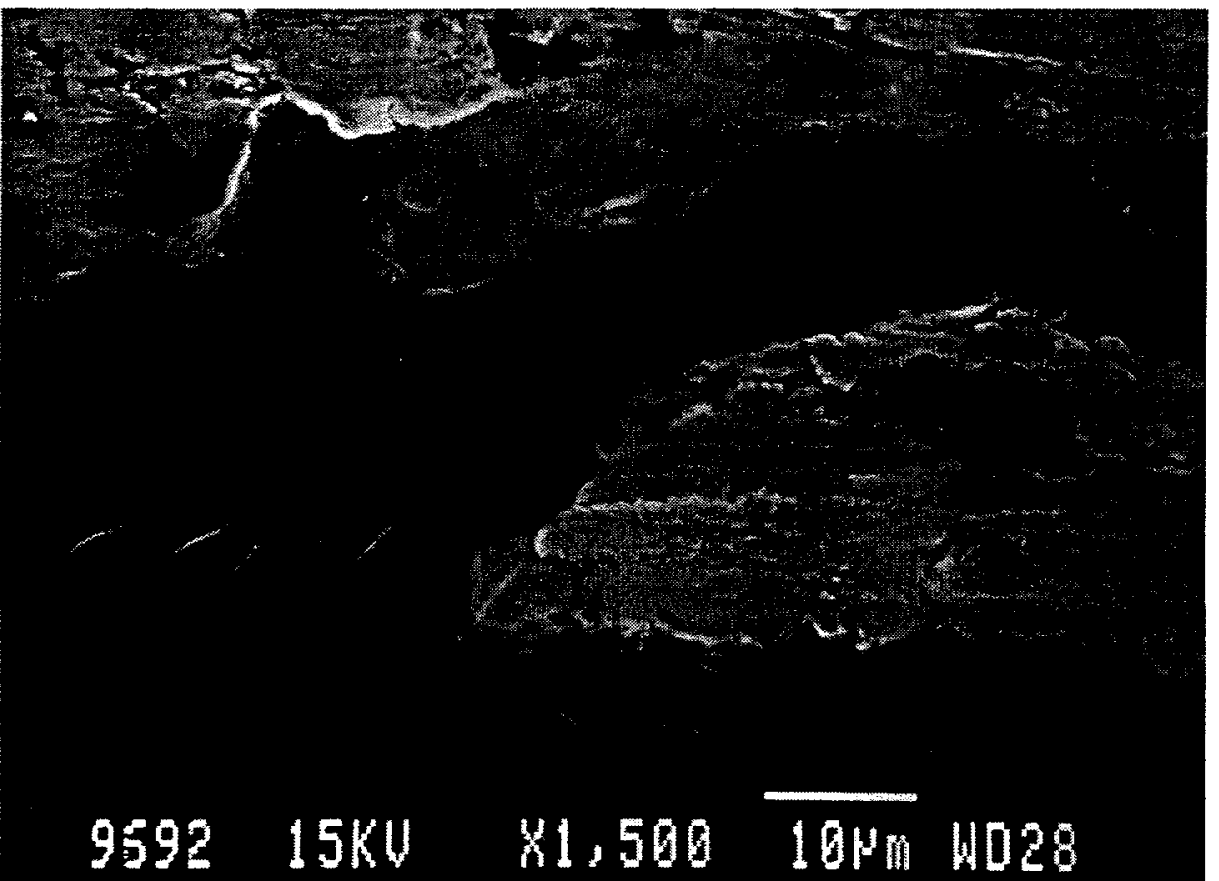

Figure 12: Edge of track on coated surface showing cracking and spalling as another mechanism of coating removal. 